\title{
Review of Resource Utilization Technology of Steel Slag and Carbon Capture Utilization
}

\author{
Zheng Qiao $^{1}$ \\ ${ }^{1}$ College of Environmental Science and Engineering, Nankai University, 300071, China
}

\begin{abstract}
Steel slag is a kind of alkaline solid waste produced in the process of steel production. In China, the annual steel slag production is very large but the utilization rate is only $20 \%$. Therefore, technologies disposing steel slag effectively need to be developed. In traditional resource utilization technology, steel slag is used in sintering flux, road construction, cement and concrete production, preparation of glass ceramics and agriculture. In these fields, we mainly give full play to steel slag's mechanical properties. Although these traditional technologies are simple and easy to use, the main reason for their limited application is the low value of resource-based products and the lack of market competitiveness. Therefore, some new exploration has been made on the resource utilization of steel slag, including dephosphorization of sewage, heavy metal adsorption, hazardous gas removal, fixed $\mathrm{CO}_{2}$ by mineral carbonation. Compared with the traditional resource utilization technologies, these new technologies mainly utilize the physical and chemical properties of steel slag, such as alkalinity and pore characteristics. However, these new technologies also have some limitations, so it is necessary to develop a resource-based technology with strong pertinency, large consumption and high added value of products to treat steel slag. Carbon dioxide is the most important greenhouse gas leading to global climate change. At present, China's carbon dioxide emissions are high, so it is urgent to develop effective carbon dioxide emission reduction technology. In recent years, carbon capture, utilization and storage (CCUS) technology has received extensive attention. This paper summarizes the carbon capture utilization and sequestration technology, and discusses its problems at present.
\end{abstract}

\section{Introduction}

Steel slag, also known as slag of steelmaking, is a kind of alkaline solid waste produced in the process of steel production. Typical integrated steel production process and steel slag production diagram was shown in Figure 1.(a). For every ton of coarse steel produced, there are approximately $150-250 \mathrm{~kg}$ of steel slag. According to the method of steelmaking, it is divided into converter slag, flat slag and electric slag[1]. As shown in Figure 1.(b), with the economic development in recent years, crude steel output has increased year by year, so the output of steel slag has also increased year by year. Since the $21^{\text {st }}$ century, the global annual production of steel slag is 130-200 million tons[2]. As shown in Figure 1.(c), China is the country with the largest steel production in the world, accounting for more than half of the world's steel production. In 2012, China's steel slag production was 93 million tons, but its utilization rate was only $20 \%$. In addition to a small amount used for cement production and road construction, a large amount of steel slag was stored in the open air[3]. If not dealt with, not only will waste land resources, but also will produce dust and air pollution problems[4], among which alkaline substances entering water will also lead to pollution. Generally speaking, the density of steel slag does not exceed $3.5 \mathrm{~g} / \mathrm{cm}^{3}$. Steel slag is composed of a variety of minerals. The main components are: calcium oxide, silicon oxide, magnesium oxide, alumina and a part of ferrous oxide[5]. Due to the close production process, the steel slag composition of most of China's steel mills is close, and due to high content of heavy metals, it is relatively difficult to reuse. 


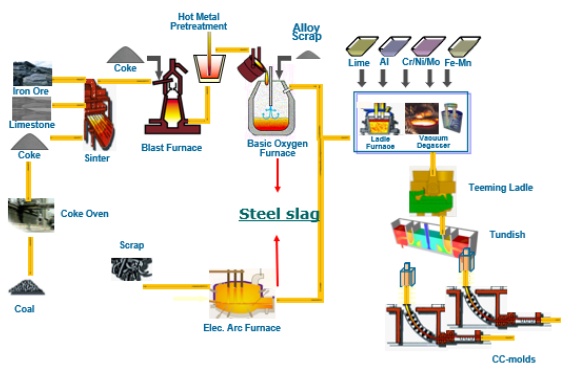

(a)

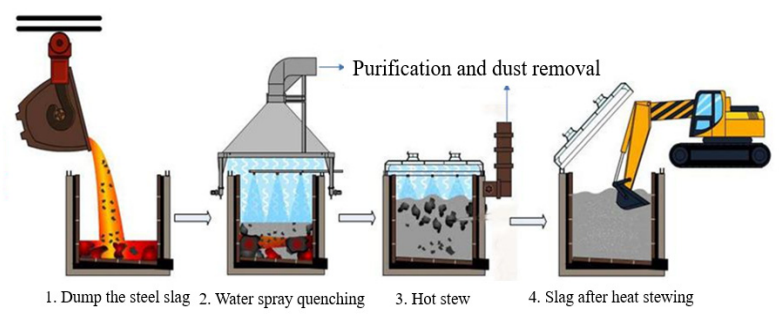

(b)

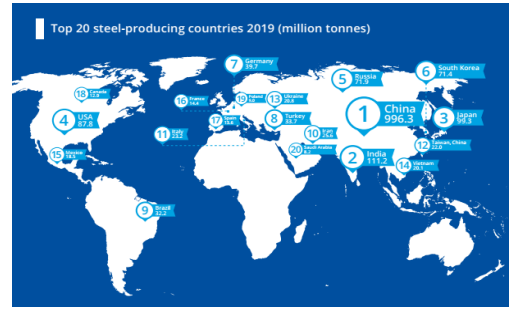

(c)

Figure 1. (a) Typical integrated steel production process and steel slag production diagram (b) The world crude steel production 1950-2019 (c) Top 20 steel-producing courtries 2019

The current utilization rate of steel slag in China is low, and the annual utilization is less than 20 million tons. The current main utilization method is to make steel slag powder, steel slag cement and steel slag bricks, which are used as ingredients for sintered ore or Portland cement clinker in steel plants.. Among them, the proportion of steel slag used for steel slag bricks and road materials is the largest, close to $40 \%$; it is used for steel slag powder and sinter ore ingredients next, each accounting for about $20 \%$. In fact, the treatment of steel slag is also a problem for western developed countries. In the United Kingdom, only about $10 \%$ of steel slag is used as resources, and the other $90 \%$ is stored in open storage or landfill.

\section{Rreview of steel slag resource utilization technology}

\subsection{Traditional resource utilization technology of steel slag}

The traditional way of steel slag recycling mainly includes the following aspects[6-8]

(1) Heat stewing process

The heat stewing process refers to heat-simmering the steel slag in the corresponding container under the conditions of steam and pressure, as shown in Figure 2. The reaction mechanism of the hot slag steel slag process includes physical changes and chemical reactions. Physical change refers to the rapid cooling of high-temperature steel slag when it encounters water vapor. Due to the different expansion coefficients of steel and slag, uneven cooling shrinkage occurs, causing the slag shell to burst apart. In addition, as the temperature of the steel slag decreases, the hydraulic mineral $\mathrm{C}_{3} \mathrm{~S}$ in the slag begins to undergo crystal transformation, expands in volume, and the steel slag is further pulverized. The above physical changes are the basis for the steel slag hot stuffing process to achieve slag steel separation. The crystal transformation process of hydraulic mineral $\mathrm{C}_{3} \mathrm{~S}$ is as follows: $\mathrm{C}_{3} \mathrm{~S}-\mathrm{C}_{2} \mathrm{~S}+\mathrm{CaO}$. The chemical reaction means that the free calcium oxide and magnesium oxide in the steel slag undergo a hydrolysis reaction with water vapor. This hydrolysis reaction eliminates the instability of steel slag and is the basis for the resource utilization of steel slag. The specific reaction is: $\mathrm{CaO}+\mathrm{H}_{2} \mathrm{O}=\mathrm{Ca}(\mathrm{HO})_{2}$, volume expansion of $97.8 \% ; \mathrm{MgO}+\mathrm{H}_{2} \mathrm{O}==\mathrm{Mg}(\mathrm{HO})_{2}$, volume expansion of $148 \%$. The steel slag processed by heat brazing contains less amount of unstable mineral phases, the particle size of the steel slag particles is smaller, and it is easy to be processed later. However, this method is worthy of high energy consumption, large area of the processing system and long time consumption.

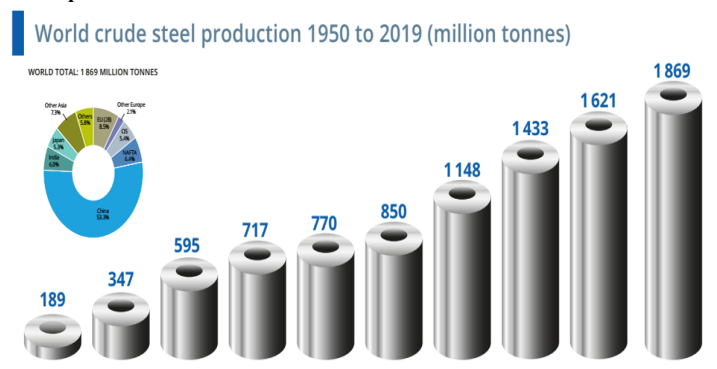

Figure 2. The general process of heat stewing method

(2) Sintering flux

The production of sinter needs adding lime as flux. The content of calcium element in steel slag is relatively high, and it can be processed into steel slag powder with particle size less than $10 \mathrm{~mm}$, which can replace part of limestone as sintering material [9], at the same time, the drum index and caking rate can be increased, which is conducive to the sintering and pelletizing process and the sintering speed [10]. Bao-steel began to return steel slag to sinter burden in 1996, which can consume 150000 tons of steel slag every year [11].

(3) Road construction

Steel slag has good wear resistance and compression resistance. Therefore, the steel slag with stable properties 
after aging can be used as subgrade material. In Japan and some parts of Europe, about $60 \%$ of steel slag is used in road engineering [9]. SAS et al. [12] cited field tests to prove that steel slag can meet the strength requirements of road base and pavement. Ahmedz ade et al [13] proved that steel slag as coarse aggregate can improve the mechanical properties of asphalt mixture. The research on the application of steel slag in road engineering started earlier in China. In 2009, 1275 tons of steel slag asphalt mixture was used in the overhaul of Chang'an Street in Beijing, and the road is in good condition [14]. In 2011, a $800 \mathrm{~m}$ long and $7.5 \mathrm{~m}$ wide steel slag asphalt concrete test section was paved in the new project of Beiyan road of Beijing Road in Urumqi. The field test results show that the section can meet the technical requirements of the standard for quality inspection and evaluation of highway engineering [15].

The application of steel slag in road engineering mainly faces two problems: one is the hydration reaction of $\mathrm{CaO}$ and $\mathrm{MgO}$ in the steel slag, which leads to volume expansion; the other is the environmental risk caused by the leaching of trace heavy metals contained in the steel slag in the rain [9]. Therefore, the steel slag must meet the stability requirements before use, and the leaching of heavy metals shall be tested [16].

(4) Cement and concrete production

The active minerals such as three calcium silicate $\left(\mathrm{C}_{3} \mathrm{~S}\right)$ and two calcium silicate $\left(\mathrm{C}_{2} \mathrm{~S}\right)$ in steel slag have certain hydrogel [17], which are suitable raw materials for cement production. Altun et al. [18] have proved that the cement mixed with $30 \%$ steel slag powder will not significantly affect its performance. Wen Xilian et al. [19] found that the concrete with compressive strength of $100 \mathrm{MPa}$ and strong resistance to chloride ion penetration can be prepared by adding steel slag into the concrete

(5) Preparation of glass ceramics

The research and development of glass ceramics began in the 1960s. At present, the difference between large-scale production of [20] glass ceramics and ordinary glass is that micro nucleating agent is added in the preparation process, so the crystallization process can be controlled. The mechanical strength of the product is higher than that of ordinary glass, and the performance of wear resistance, corrosion resistance, weathering resistance, thermal shock resistance is better [21]. At present, there is much research on the preparation of glass ceramics, such as the influence of crystallization time [22], additives [23], sintering atmosphere [24] and other factors on the properties of glass ceramics

(6) Agriculture

Because the steel slag has strong alkalinity, the Cao and $\mathrm{MgO}$ contained in it can neutralize the soil acidity, so the steel slag can be used for the soil improvement of acid soil [25]. Compared with lime to neutralize soil acidity, steel slag has better soil improvement effect because it contains a certain amount of soluble magnesium and phosphorus [26]. In addition, the steel slag with high phosphorus content can be used to prepare phosphate fertilizer, supplement soil nutrients, and increase soil yield; the converter steel slag with more than $15 \% \mathrm{SiO}_{2}$ can be used as silicon fertilizer after being ground to less than 60 mesh; the steel slag also contains other microelements such as iron and manganese, which can be made into slow-release microelement fertilizer [26].

The traditional utilization technology of steel slag is mainly to give full play to its mechanical properties. After simple mechanical or heat treatment, it can be made into steel slag cement, steel slag brick and other road or building materials for application. Although these traditional technologies are simple and easy to use, the main reason for their limited application is the low value of resource-based products and the lack of market competitiveness.

\subsection{New resource utilization technology of steel slag}

\section{(1) Dephosphorization of sewage}

In recent years, the use of steel slag to remove inorganic phosphorus $(\mathrm{P})$ from sewage has been reported more and more at home and abroad. Xue [27] studied the mechanism of BOF slag removal of $\mathrm{P}$ in sewage by using the sequential batch leaching reactor, and investigated the effect of $\mathrm{pH}$ value on the phosphorus removal effect of slag. Claveau- Mallet et al. [28] used EAF steel slag as filter media to remove $P$ from sewage, and established a dynamic model of steel slag phosphorus removal based on the mechanism of precipitation and crystallization. On this basis, the effects of $\mathrm{P}$ concentration, inorganic carbon concentration and hydraulic retention time on the filter material (steel slag) life and phosphorus removal effect were investigated through experiments, and the model parameters were determined by computer simulation [29]. Barca [30] carried out a two-year field test on a small wetland system with steel slag as the filter material. The removal rates of total phosphorus by EAF slag and converter slag can reach $37 \%$ and $62 \%$ respectively.

(2) Heavy metal adsorption

Steel slag has porous structure and large specific surface area, and it is easy to separate from water because of its high density, which provides the possibility for its application in heavy metal adsorption in sewage. The results show that the steel slag has good adsorption effect on many heavy metals in sewage, such as $\mathrm{CrO}_{4}$ [31], $\mathrm{Cu}^{2+}$ [32], $\mathrm{Pb}^{2+}$ [33], $\mathrm{As}^{5+}$ [34] and $\mathrm{Cd}^{2+}$ [35]

(3) Hazardous gas removal

Steel slag has a good degradation effect on some harmful gases such as $\mathrm{H}_{2} \mathrm{~S}$. Asaoka et al. [36] pointed out that $\mathrm{MnO}$ in steel slag can oxidize and remove $\mathrm{H}_{2} \mathrm{~S}$ dissolved in water. Montes Moran et al. [37] found that the removal effect of steel slag on $\mathrm{H}_{2} \mathrm{~S}$ gas can reach 180 $\mathrm{mg} \mathrm{H}_{2} \mathrm{~S} / \mathrm{g}$ at room temperature, and studied the influence of gas moisture content and steel slag particle size on the removal effect of $\mathrm{H}_{2} \mathrm{~S}$. Zhang et al. [38] showed that steel slag can degrade greenhouse gas $\mathrm{SF}_{6}$ more effectively than pure metal oxide.

(4) Fixed $\mathrm{CO}_{2}$ by mineral carbonation

The accelerated carbonation of industrial solid wastes rich in calcium and magnesium, such as steel slag, can directly fix $\mathrm{CO}_{2}$ in the form of carbonate. It is the 
research hotspot of the fixed technology of carbonation of $\mathrm{CO}_{2}$ minerals [39-40]. As a kind of typical bulk calcium based industrial solid waste, the $\mathrm{CO}_{2}$ fixation potential of steel slag can reach $99-135 \mathrm{~kg} / \mathrm{T}$ [2].

Huijgen et al. [41] first studied the Carbonation Mechanism of fixing $\mathrm{CO}_{2}$ with steel slag as raw material. Bonenfant et al. [42] studied the effect of two types of steel slag, furnace slag and casting residual slag, on $\mathrm{CO}_{2}$ fixation at room temperature and atmospheric pressure. The results show that the $\mathrm{CO}_{2}$ fixation capacity of the slag is $247 \mathrm{~g} \mathrm{CO}_{2} / \mathrm{kg}, 14$ times that of the slag. The difference of free calcium hydroxide content in two kinds of steel slag is the key factor that leads to the difference of $\mathrm{CO}_{2}$ fixation capacity. Chang et al. [43-44] studied in detail the effects of operating parameters such as slag type, reaction time, reaction temperature, flow rate of $\mathrm{CO}_{2}$ gas, liquid-solid ratio, partial pressure of $\mathrm{CO}_{2}$ and initial $\mathrm{pH}$ on $\mathrm{CO}_{2}$ fixation by carbonation of slag solution. The results show that compared with other types of slag, converter slag has a better $\mathrm{CO}_{2}$ fixation effect, and its carbonation rate can reach $72 \%$ under the optimal reaction conditions. They also pointed out that reaction temperature and reaction time are the two most important factors affecting the effect of carbonation of steel slag solution on $\mathrm{CO}_{2}$ fixation. The reaction kinetics mechanism of carbonation between steel slag and $\mathrm{CO}_{2}$ solution was explained by using the shrinking core model and surface coverage model. Yu et al. [45] investigated the fixation effect of high temperature direct gas-solid carbonation of converter slag and electric furnace slag on $\mathrm{CO}_{2}$. The results showed that the fixation effect of electric furnace slag on $\mathrm{CO}_{2}$ in direct gas-solid carbonation mode was better than that of converter slag. They believe that temperature and $\mathrm{CO} 2$ concentration are the key factors affecting the reaction process. In China, Bao Weijun [46] has carried out in-depth research on the indirect carbonation of $\mathrm{CO}_{2}$ wet process with converter slag as raw material. The proposed process of carbonation separation recovery coupling strengthening can increase the carbonation conversion rate of the indirect route to $50 \%$ with acetic acid as extraction agent.

In conclusion, accelerated (enhanced) carbonation of calcium based industrial solid wastes such as steel slag can effectively fix $\mathrm{CO}_{2}$. However, the amount of industrial solid waste that can be used to fix $\mathrm{CO}_{2}$ by carbonation is significantly less than that of natural minerals, so its absolute fixed capacity of $\mathrm{CO}_{2}$ is far less than that of natural minerals. According to statistics, at present, the global fixed $\mathrm{CO}_{2}$ potential of steel slag is 440-59 million tons per year, and this amount is only about $5 \%$ of the annual $\mathrm{CO}_{2}$ emissions of steel plants in China. Therefore, how to improve the total $\mathrm{CO}_{2}$ capture capacity of industrial solid wastes such as steel slag is the focus of future research in this field.

\subsection{Technical bottlenecks in the development of steel slag resource utilization technology}

In general, at present, in the field of application, the comprehensive utilization technology of steel slag at home and abroad mainly focuses on giving full play to its good mechanical strength and hydrothermal stability, and applying it to the road construction and construction industry after simple mechanical or heat treatment, which is a simple and easy way to absorb steel slag. However, due to the low self value and added value of these resources products, the lack of market competitiveness and market power, the utilization rate (consumption) of steel slag is limited.

Therefore, in the field of laboratory research, the research of steel slag recycling technology has been transferred from the first generation technology of preparing building or subgrade materials with a small amount of doping to the second generation technology of utilizing the physical and chemical properties of steel slag, such as alkalinity and pore properties. However, this kind of technology, which aims at adsorption or removal of pollutants and uses steel slag as a whole, can not guarantee the reduction and harmlessness of steel slag, so the treatment and disposal of steel slag after resource-based utilization becomes a great problem. At the same time, steel slag has no significant performance advantage compared with other materials.

Therefore, it is the main task for the development of comprehensive utilization of steel slag at home and abroad to develop a resource-based technology with strong pertinence, considerable consumption and high added value of products. Since the 12th Five Year Plan, China has issued the 12th Five Year Plan for comprehensive utilization of large amount of industrial solid waste, which clearly puts forward the requirements of high added value and high-grade utilization of industrial solid waste recycling technology in the future. Based on the idea of deep utilization of materials or elements in steel slag, resource-based technology characterized by extraction and recovery of elements in steel slag should be the development direction of comprehensive utilization technology of steel slag in the future.

\section{Development status of industrial source $\mathrm{CO}_{2}$ emission reduction technology}

$\mathrm{CO}_{2}$ emitted by human activities is the primary greenhouse gas that causes global climate change [47]. The concentration of $\mathrm{CO}_{2}$ in the atmosphere has rapidly increased from $280 \mathrm{Pm}$ before the industrial revolution to $390 \mathrm{ppm}$ [48]. If the concentration of $\mathrm{CO}_{2}$ in the atmosphere exceeds $550 \mathrm{ppm}$, it may cause significant damage to the environment [49]. China's current annual $\mathrm{CO}_{2}$ emissions have exceeded 10 billion tons [50], ranking first in the world.

At present, $\mathrm{CO}_{2}$ emissions from industrial sources are close to $40 \%$ of the global annual $\mathrm{CO}_{2}$ emissions, making it the world's largest source of $\mathrm{CO}_{2}$ emissions [51]. Among them, the steel industry is the world's largest energy-consuming production industry [52]. The average production of $1 \mathrm{t}$ of crude steel will cause about $2 \mathrm{t} \mathrm{CO}_{2}$ emissions. The current annual $\mathrm{CO}_{2}$ emissions of the global steel industry have exceeded 2.5 billion tons, accounting for about $5 \%$ of the total global $\mathrm{CO}_{2}$ 
emissions [53]. China has become the world's largest steel producer and the country with the highest $\mathrm{CO}_{2}$ emissions in the steel industry. Since 2006, the annual $\mathrm{CO}_{2}$ emissions of China's steel industry have exceeded 1 billion tons, accounting for about $10 \%$ of the country's total $\mathrm{CO}_{2}$ emissions [54]. In order to effectively control global climate change caused by greenhouse gas emissions, the Intergovernmental Committee on Climate Change (IPCC) has developed a 2DS plan, which requires that by 2025, the global steel industry $\mathrm{CO}_{2}$ emissions should be reduced by $13 \%$ from 2011 levels [55]. It can be seen that China's steel industry is faced with the arduous task of reducing $\mathrm{CO}_{2}$ emissions, and the development of $\mathrm{CO}_{2}$ emission reduction technologies suitable for the characteristics of the steel industry is imminent in China.

\section{Proposal of Coupling of Carbon Dioxide with Hot Steel Slag}

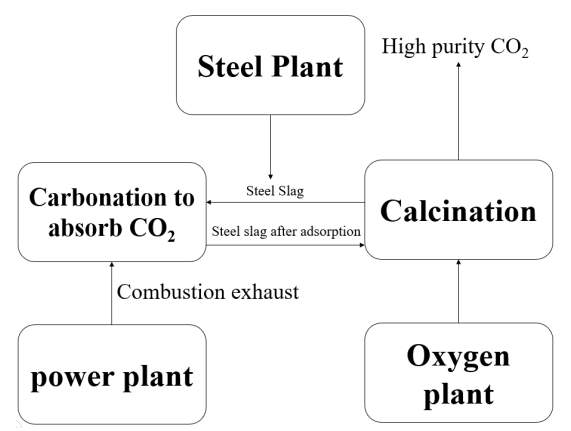

Figure 3. Technology Roadmap

In view of the two major challenges faced by my country's steel industry, high-grade comprehensive utilization of steel slag and $\mathrm{CO}_{2}$ emission reduction. In order to meet the demand, this paper aims at the high-grade resource utilization of steel slag, and designs a coupling utilization route of high-grade comprehensive utilization of steel slag and $\mathrm{CO}_{2}$ emission reduction as shown in Figure 3. The main basis for adsorbing and capturing $\mathrm{CO}_{2}$ using steel slag is the following equation:

$\mathrm{CaO}(\mathrm{s})+\mathrm{CO}_{2}(\mathrm{~g})=\mathrm{CaCO}_{3}(\mathrm{~s})$

The thermodynamics of this reaction can be described by the following equation:

$\log _{10} \mathrm{P}_{\mathrm{CO} 2}[\mathrm{~atm}]=7.079-(8308 / \mathrm{T}[\mathrm{K}])$

Carry out research on the preparation of high-efficiency calcium-based $\mathrm{CO}_{2}$ adsorption materials using steel slag as raw materials, and apply it to in-situ $\mathrm{CO}_{2}$ capture in the steel industry. Therefore, while achieving the reduction of $\mathrm{CO}_{2}$ emissions in the steel industry, the purpose of recycling calcium and iron in steel slag is achieved, and waste is used to treat waste and clean production, thereby achieving the unification of environmental benefits, economic benefits, and social benefits, for the high-value utilization of steel slag Provides new research ideas. In the future, the following experiments and research can be carried out:

1. Experimental study on direct fixation of $\mathrm{CO}_{2}$ by high temperature gas-solid carbonation of steel slag. Aiming at the problem that the current research does not understand the theory and reaction kinetic characteristics of steel slag carbonation, systematically study the effect, influencing factors and reaction kinetic characteristics of high temperature gas-solid carbonation directly fixing $\mathrm{CO}_{2}$, and experimentally determine the theoretical $\mathrm{CO}_{2}$ fixing potential of steel slag, A particle first-order reaction kinetics composite Kingstinger diffusion model was proposed to analyze the kinetic characteristics and reaction parameters of high-temperature gas-solid carbonation of steel slag, and explore the $\mathrm{CO}_{2}$ capture effect of steel slag in the high-temperature calcium cycle mode.

2. Element leaching characteristics of steel slag and recovery of calcium and iron elements. Aiming at the limiting factor of the low ratio of activated calcium that can be used for carbonation and fixation of $\mathrm{CO}_{2}$ in steel slag, with the goal of the separation and recovery of calcium and iron elements in steel slag, a system was developed on the acid leaching characteristics of each element in steel slag and its influencing factors Experimental research. On this basis, the process parameters of acid leaching of calcium element in steel slag and magnetic separation of iron element were optimized.

3. Preparation of calcium-based $\mathrm{CO}_{2}$ adsorption material and its $\mathrm{CO}_{2}$ adsorption performance by steel slag. Using steel slag as the raw material, a calcium-based $\mathrm{CO}_{2}$ adsorption material was prepared by a collaborative precipitation method, and the physicochemical properties and $\mathrm{CO}_{2}$ adsorption properties of the material were systematically characterized. The paper also studied the influencing factors of the capture of $\mathrm{CO}_{2}$ in the calcium slag source calcium-based $\mathrm{CO}_{2}$ adsorbent material in the high-temperature calcium cycle mode. The preliminary technical and economic analysis of the source calcium-based $\mathrm{CO}_{2}$ adsorption material used in carbon capture in the steel industry.

\section{Conclusion}

The global steel slag production is large, but utilization rate is low. The products produced by the traditional steel slag treatment methods have low added value and poor market competitiveness. Therefore, efficient and high value-added steel slag treatment technology is urgently needed at the present. In this paper, the technology of steel slag reduction for carbon dioxide capture using steel slag is discussed, and the technical route of the treatment process is designed and the future research direction is provided.

\section{References}

1. Gahan C S. Cunha M L. Sandstrom A. Comparative study on different steel slags as neutralising agent in bioleaching [J]. Hydrometallurgy, 2009 95(3-4): 190-197

2. Renforth P,Washbourne C L, Taylder J, et al. Silicate production and availability for mineral carbonation $[\mathrm{J}]$. Environmental Science \&Technology ,2011, 45(6): 2035-2041 
3. China Steel Industry Yearbook 2013R

4. Navarro C, Diaz M , Villa-Garcia M A . Physico-Chemical Characterization of Steel Slag. Study of its Behavior under Simulated Environmental Conditions[J]. Environmental Science \& Technology, 2010, 44(14): P.5383-5388.

5. Ye Bin. Process technology and industrialization of converter steel slag gas crushing [D]. Metallurgical Engineering of Chongqing University. 2003

6. Yang Huaming, Cui Jianli, Zhao $\mathrm{Wu}$, et al. Research progress of comprehensive treatment of "three wastes" in iron and steel plants[J]. Angang Technology, 201(1): 1-7

7. van Zomeren A, van der Laan S R, Kobesen H B $\mathrm{A}$, et al. Changes in mineralogical and leaching properties of converter steel slag resulting from accelerated carbonation at low Copressure[J]. Waste Management, 2011, 31(11): 2236-2244

8. Poh H Y, Ghataora G S , Ghazireh N . Soil Stabilization Using Basic Oxygen Steel Slag Fines[J]. Journal of Materials in Civil Engineering, 2006, 18(2):229-240.

9. Yi $\mathrm{H}, \mathrm{Xu} \mathrm{G}$, Cheng $\mathrm{H}$, et al. An overview of utilization of steel slag[J]. Procedia Environmental Sciences,2012,16:791-80

10. Zhang Geng. Status of comprehensive utilization of Baosteel steel slag [J]. Baosteel Technology, 2006(1): 20-24.

11. Sas W, Gluchowski A, Radziemska M, et al. Environmental and geotechnical assessment of the steel slags as a material for road structure[ $\mathrm{J}]$. Materials, 2015, 8(8): 4857-4875

12. Ahmedzade P, Sengoz B. Evaluation of steel slag coarse aggregate in hot mix asphalt concrete[J]. Journal of Hazardous Materials, 2009, 165(1-3): 300-305

13. Liu Hao, Ding Jianping, Li Zhenguo, et al. Application of new materials in the pavement overhaul project of Chang' an Street in Beijing [J]. Municipal Technology, 2010, 28(1): 23-25, 29

14. Qi Guanghe. Application of Steel Slag Asphalt Mixture in Urumqi Municipal Road Engineering[J]. Highway Transportation Technology (Application Technology Edition), 2014(03):122-124.

15. Huang Yi, Status of the application of steel slag in road engineering: 2014 National Metallurgical Energy Environmental Protection Production Technology Association, Wuhan 2014[C]

16. Zhao Junxue, Li Xiaoming, Tang Wenxian, et al. Comprehensive utilization technology and progress analysis of steel slag[J]. Angang Technology, 2013(3): 1-6.24.

17. Altun I A, Yilmaz I. Study on steel fumace slags with high Mgo as additive in Portland cement [J]
Cement and Concrete Research 2002, 32(PIS0008-8846(02)000763-98):1247-1249

18. Wen Xilian, Ouyang Dong, Pan Pan. Research on C100 high chloride ion permeability concrete prepared by steel slag composite admixture[J]. Concrete, 2011(06): 73-75.

19. Zhang Zhaohui, Liao Jielong, Ju Jiantao, et al. Steel slag treatment process and steel slag utilization technology at home and abroad [J]. Journal of Iron and Steel Research, 2013, 25(7): 14.

20. Nan Xueli. Development of glass-ceramics [D]. Materials Science of Lanzhou University of Technology, 2006.

21. Zhang Kai, Wu Wenfei, Li Baowei. The effect of crystallization time on the structure and properties of steel slag glass-ceramics [J]. Journal of Huazhong University of Science and Technology (Natural Science Edition), 2014(5):71-74.

22. Yao Qiang, Lu Lei, Jiang Qin, et al. Effect of additives on bending strength and color of steel slag glass-ceramics [J] Silicate Bulletin 2005, 24(4): 104-106

23. Li Yu, Zhang Lingling, Wang Yang, etc. The influence of sintering atmosphere on the properties of steel slag glass-ceramic composites: the 17th National Annual Conference of High-Tech Ceramics, Nanjing, 2012[C]

24. Makela M, Watkins G, Poykio R, et al. Utilization of steel, pulp and paaper industry solid residues in forest soil amendment: relevant physicochemical properties and heavy metal availability [J]. Journal of Hazardous Materials, 2012, 207(S1): 21-27.

25. Wu Zhihong, Zou Zongshu, Wang Chengzhi. Reuse of converter steel slag in agricultural production $[\mathrm{J}]$. Comprehensive Utilization of Mineral Resources 2005(6): 25-28.

26. Xue Y, Hou H, Zhu S. Characteristics and mechanisms of phosphate adsorption onto basic oxygen furnace $\operatorname{slag}[\mathrm{J}]$. Journal of Hazardous Materials, 2009, 162(2-3): 973-980

27. Claveau-mallet D, Wallace S, Comeau Y. Model of phosphorus precipitation and crystal formation in electric arc furnace steel slag filters [J]. Environmental Science Technology 2012, 46(3):1465-1470.

28. Claveau-mallet D, Courcelles B, Comeau Y Phosphorus removal by steel slag filters: modeling dissolution and precipitation kinetics to predict longevity $[\mathrm{J}]$ Environmental Science Technology,2014,.48(13):7486-7493.

29. Barca C, Troesch S, Meyer D, et al. Steel slag filters to upgrade phosphorus removal in constructed wetlands: two years of field experiments $[\mathrm{J}]$. Environmental Science \&Technology, 2013,47(1):549-556

30. Ochola C E, Moo-young H K. Establishing and elucidating reduction as the removal mechanism 
of $\mathrm{Cr}(\mathrm{VI})$ by reclaimed limestone residual RLR (modified steel slag) $[\mathrm{J}]$. Environmental Science \&Technology, 2004,38(22): 6161-6165

31. Kim D, Shin M, Choi H, et al. Removal mechanisms of copper using steel-making slag adsorption and precipitation [J]. Desalination, 2008, 223(1-3): 283-289

32. Liu S, Gao J, Yang Y, et al. Adsorption intrinsic kinetics and isotherms of lead ions on steel slag $[\mathrm{J}]$ Journal of Hazardous Materials, 2010, 173(1-3): 558-562.

33. Oh $\mathrm{C}$, Rhee $\mathrm{S}$, Oh $\mathrm{M}$, et al. Removal characteristics of $\mathrm{A}(\mathrm{II})$ and $\mathrm{A}(\mathrm{V})$ from acidic aqueous solution by steel making slag[J]. Journal of Hazardous Materials, 2012, 213: 147-155

34. Jinming D, Bing $S$ Removal characteristics of $\mathrm{Cd}$ ( ID) from acidic aqueous solution by modified steel-making slag [J]. Chemical Engineering Journal, 2014, 246: 160-167

35. Asaoka S, Okamura H, Morisawa $\mathrm{R}$, et al. Removal of hydrogen sulfide using carbonated steel Slag[J]. Chemical Engineering Journal, 2013, 228: $843-849$

36. Montes-moran M A, Conches A, Canals-batlle C, et al. Linz-donawitz steel slag for the removal of hydrogen sulfide at room temperature $[\mathrm{J}]$. Environmental Science Technology 2012,46(16):8992-8997

37. Zhang J, Zhou J Z, Xu Z P, et al. Decomposition of potent greenhouse gas sulfur hexafluoride (SF6)by kirschsteinite-dominant stainless steel slag [J]. Environmental Science\&Technology, 2014,48(1):599-606.

38. Sanna A, Dri M, Hall M R, et al. Waste materials for carbon capture and storage by mineralisation (CCSM)A UK perspective[J]. Applied Energy, 2012, 99: 545-554

39. Gunning P J, Hills C D, Carey P J. Accelerated carbonation treatment of industrial wastes $[\mathrm{J}]$ Waste Management. 2010.30(6): 1081-1090

40. Huijgen W J, Comans R N J. Mineral CO2 sequestration by steel slag carbonation $[\mathrm{J}]$ Environmental Science Technology, 2005, 39(24): 9676-9682

41. Bonenfant D, Kharoune L, Sauve S, et al. CO sequest ration potential of steel slags at ambient pressure and temperature $[\mathrm{J}]$ Industrial Engineering Chemistry Research, 2008, 47(20):7610-7616.

42. Chang E E, Chen C, Chen Y, et al. Performance evaluation for carbonation of steel-making slags in a slurry reactor[J]. Journal of Hazardous Materials, 2011, 186(1): 558-564

43. Chang EE, Pan S, Chen Y, et al. CO sequestration by carbonation of steelmaking slags in an autoclave reactor. Journal of Hazardous Materials. 20 t195: 107-114.
44. Yu J, Wang K. Study on characteristics of steel slag for CO capture [J]. Energy Fuels, 2011 25(11):5483-5492

45. Bao Weijun, Li Huiquan, Zhang Yi. Research progress of carbonation fixation of greenhouse gas $\mathrm{CO} 2$ minerals $[\mathrm{J}]$. Journal of Chemical Engineering, 2007, 8(1): 1-9.

46. Raupach M R, Marland G, Ciais P, et al. Global and regional drivers of accelerating $\mathrm{CO} 2$ emissions[J]. Proc Natl Acad Sci U S A, 2007, 104(24): 10288-10293.

47. IPCC. Climate change 2013: the physical science basis. Contribution of working group I to the fifth assessment report of the intergovernmental panel on climate change[R]. Cambridge,United Kingdom and New York, NY, USA: 2013.

48. Bertos M F, Li X, Simons S, et al. Investigation of accelerated carbonation for the stabilization of MSW incinerator ashes and the sequestration of CO2 [U]. Green Chemistry, 2004, 6(8):428-436.

49. Liu Z, Guan D, Wei W, et al. Reduced carbon emission estimates from fossil fuel combustion and cement production in China [J]. Nature, 2015, 524(7565): 335-338.

50. Napp T A, Gambhir A, Hills T P, et al. A review of the technologies, economics and policy instruments for decarbonising energy-intensive manufacturing industries[J]. Renewable and Sustainable Energy Reviews, 2014, 30: 616-640.

51. Ho M T, Bustamante A, Wiley D E. Comparison of $\mathrm{CO} 2$ capture economics for iron and steel mills[J]. International Journal of Greenhouse Gas Control, 2013, 19: 145-159.

52. Oda J, Akimoto K, Tomoda T, et al. International comparisons of energy efficiency in power, steel, and cement industries[J]. Energy Policy, 2012, 44: 118-129.

53. Han Ying, Li Lianshui, Sun Ning. Research on carbon dioxide emissions of China's iron and steel industry $[\mathrm{J}]$ Journal of Nanjing University of Information Science and Technology (Natural Science Edition), 2011(01):53-57.

54. Internat ional Energy Agency(EA). Tracking clean energy progress $2014[\mathrm{M}] .2014$. 